\title{
Düşük Reynolds sayılı alveolar akışta partikül boyutunun aerosol dinamikleri üzerine etkisinin sayısal olarak incelenmesi
}

\author{
Numerical analysis of the particle size effect on aerosol dynamics in low Reynolds number \\ alveolar flow
}

Doğan ÇiLOĞLU* ${ }^{* 1, a}$

${ }^{1}$ Atatürk Üniversitesi, Teknik Bilimler Meslek Yüksekokulu, Elektrik ve Enerji Bölümü, 25240, Erzurum

• Geliş tarihi / Received: 19.01.2021 • • Düzeltilerek geliş tarihi / Received in revised form: 27.04.2021 • Kabul tarihi / Accepted: 15.05 .2021

\begin{abstract}
Öz
Akciğer hastalıklarında etkili bir tedavi yönteminin geliştirilmesi ve ilaç taşınımının iyileştirilmesi açısından akciğerlerin asiner bölgesindeki hava akışının ve solunan farmasötik veya zararlı partiküllerin taşınmasının incelenmesi çok önemlidir. $\mathrm{Bu}$ çalışmada, insan akciğerinin asiner bölgesinde etrafı alveol keseleri ile çevrilmiş bir respiratuar bronşiol modeli üzerinde alveolar hava akışı ve farklı boyutlardaki partiküllerin aerosol dinamikleri üzerine etkisi hesaplamalı akışkanlar dinamiği (CFD) kullanılarak sayısal olarak incelenmiştir. Sayısal simülasyonlar, çoklu nefes periyotları ve üç farklı solunum şartı (düşük, normal ve ağır solunum) için yapılmıştır. Her bir akış durumunda model girişinden hesap alanına farklı çaplara sahip aerosol partikülleri salınmış ve yörüngeleri sayısal olarak takip edilmiştir. Sonuçlar, hareketli alveol duvarları sayesinde alveol çukurlarına hava ve partikül girişinin olduğunu göstermiştir. Alveol çukurunda meydana gelen resirkülasyonlu akış yapılarının partikül dinamiklerini karakterize ettiği belirlenmiştir. Elde edilen sonuçlara göre model içerisinde kalan aerosol miktarı, partikül boyutu ve akış debisiyle azalmıştır. $7 \mu$ m'nin üzerinde çapa sahip aerosol partiküllerinin kanal cidarlarında ve $5 \mu \mathrm{m}$ 'nin altındaki partiküllerin ise alveol boşluklarında biriktiği belirlenmiş̧ir. Sonuç olarak bu çalışma, solunan farmasötik veya zararlı partiküllerin alveolar bölgede davranışlarıyla ilgili önemli fizyolojik sonuçlar sunmaktadır.
\end{abstract}

Anahtar kelimeler: Asiner akış dinamiği, Düşük Reynolds sayılı akış, Resirkülasyon, Sonlu elemanlar

\begin{abstract}
In order to develop an effective treatment method and improve drug delivery in lung diseases, it is very important to examine the airflow and the transport of inhaled pharmaceutical or harmful particles in the acinar region of the lungs. In this study, the alveolar airflow and the effect of particles of different sizes on aerosol dynamics were numerically investigated on a respiratory bronchiole model surrounded by alveolar sacs in the acinar region of the human lung using computational fluid dynamics (CFD). Numerical simulations were made for multiple breathing periods and three different respiratory conditions (i.e, low, normal and heavy breathing). In each flow situation, aerosol particles with different diameters from the model entry to the computational domain were released and their trajectories were tracked numerically. The results showed that there was air and particle entry into the alveolar cavities due to the movable alveolar walls. It was determined that the recirculating flow structures occurring in the alveolus characterize the particle dynamics. According to the results, the amount of aerosol remaining in the model decreased with particle size and flow rate. It was also found that aerosol particles with a diameter of more than $7 \mu \mathrm{m}$ deposited on the duct walls and the particles below $5 \mu \mathrm{m}$ in the alveolar cavities. Consequently, this study provides the important physiological results regarding the behavior of inhaled pharmaceutical or harmful particles in the alveolar region.
\end{abstract}

Keywords: Acinar fluid dynamics, Low Reynolds number flow, Recirculation, Finite element

\footnotetext{
${ }^{\text {*a }}$ Doğan ÇíLOĞLU; dciloglu@ atauni.edu.tr; Tel: (0442) 231 26 37; orcid.org/0000-0002-7570-9271
} 


\section{Giriş}

2020 y1lı tüm dünya için Covid-19 virüsü ile mücadele y1lı olmuştur. $\mathrm{Bu}$ virüs solunum yollarıla insan vücuduna girmekte ve akciğerlere yerleşerek burada çoğalmaktadır. Bu bölgede hava kanallarının iltihaplanması ile onların tıkanmasına yol açarak birçok insanın ölümüne neden olan Coronavirus, bu hastalığı atlatan bireylerin akciğerlerinde ise "post-Covid fibrosis (hava kanallarının sivi ile dolması)" gibi ciddi kalıc1 hasarlar birakabilmektedir (George vd., 2020). Bilhassa gaz alışverişinin yapıldığı mikro boyutlarda asiner bölgede, bu ve benzeri akciğer hastalıklarının etkili tedavisinde hava akışı ve zararlı partiküllerin ya da tedavi amaçlı kullanılan aerosol partiküllerinin davranışının belirlenmesi hayati öneme sahiptir.

Solunum sistemi üst ve alt solunum sistemi olmak üzere iki kısımdan oluşmaktadır. Burun (nasus), yutak (pharynx) ve girtlak (larynx) üst solunum sistemini, soluk borusu (trachea), bronşlar (bronchi) ve respiratuar bronşioller ise alt solunum sistemini oluşturur. Bronşlar bir ağaç dallarını andıran şekliyle tüm akciğere dağılır ve solunan havanın alveollere kadar taşınmasını sağlarlar. Alveoller, solunum yollarını kismen veya tamamen kapsayan ve solunan havadaki oksijen ile kanda bulunan karbondioksitin yer değiştirdiği hava kesecikleridir. Yaklaşık $75 \mathrm{~m}^{2}$ gibi oldukça büyük bir yüzey alanına sahip olan insan akciğerleri, ortalama 480 milyon alveol bulundurmaktadır. Bir alveolün çapı ise sağlıklı bireylerde 0.2 ila $0.45 \mathrm{~mm}$ (ortalama $0.36 \mathrm{~mm}$ ) ve hasta bireylerde ise 0.46 ila $0.89 \mathrm{~mm}$ (ortalama $0.7 \mathrm{~mm}$ ) 'dir (Bennett vd., 1985; Knudsen vd., 2010). Alveoller, hava yolu ağacının 16. neslinden (G16) itibaren görünmeye başlar ve bu bölge alveolar bölge (asinus bölgesi) olarak bilinir. Alveollerin yüzeylerinde çok sayıda kılcal damar bulunmaktadır. Bu nedenle asinus bölgesi, toksik maddelerin olumsuz sağlık etkilerinin veya uygulanan farmasötik ajanların terapötik sonuçlarının değerlendirilmesinde hava hareketlerinin ve partiküllerin birikiminin belirlenmesinde kritik bir öneme sahiptir. Ancak, mikro boyutta bir alveolün gözlerden uzak konumu, karmaşı yapısı, kişiye özgü ve hareketli oluşu nedeniyle asinusta salınımlı hava akışını ve partikül dinamiklerini incelemek oldukça güçtür.

Asinus bölgesinde hava, düşük Reynolds (Re) sayılı bir akış karakteri sergilemektedir. $\mathrm{Bu}$ bölgedeki hava akışına ait Re sayıları 0.01-2 aralığında değişmektedir. Literatürde, in vivo (canlıda), in vitro (modelde) ve in siliko (sayısal) yaklaşım kullanılarak düşük Re sayılı akışlarda partikül taşınımının incelendiği birçok araştırma bulunmasına rağmen, alveol dinamikleri konusundaki bilgilerimiz hala yeterli değildir. Asinus bölgesine aerosol partiküllerinin taşınımı; farmasötik aerosollerin veya diğer ilaçların iletim stratejilerinin gelişmesinde, hedef bölgelere partiküllerin iletiminin sağlanmasında, yan etkilerinin azaltılmasında ve zararlı partikül tutulumunun değerlendirilmesinde oldukça önemlidir. Laminer bir akış koşulunun olduğu düşük Re sayılı akışların gözlendiği asinus bölgesine etkili partikül taşınımının nasıl gerçekleştĭgi konusu bu çalışmanın temelini oluşturmaktadır.

Genelde $5 \mu$ m'den küçük partiküller asinus bölgesine ulaşabilir, daha büyük partiküller ise akciğerin daha üst bölgelerinde tutunurlar (Heyder, 2004). $0.4 \mu \mathrm{m}$ 'den küçük partiküllerin hareketi taşınım ve moleküler difüzyon ile belirlenirken, 0.5 ila $4 \mu \mathrm{m}$ arasındaki partiküller taşınım ve yerçekimi kuvvetleri arasındaki denge ile belirlenir. Çap $10.5-1 \mu \mathrm{m}$ olan parçacıklar asinusta çok düşük çökme verimine sahiptir ve dağılmayan kütlesiz akışkan parçacıkları gibi davranırlar (Harrington vd., 2006). Bu boyut aralığındaki parçacıklar, çeşitli fizyolojik süreçlerde çok önemli bir rol oynamaktadırlar (Sznitman vd., 2009). Heyder vd. (1988) yaklaşık $1 \mu \mathrm{m}$ çapında partiküllerden oluşan bir aerosol bolus kullanarak sayısal olarak partikül hareketlerini incelemişlerdir. Araştırmacılar, ağız yoluyla alınan (inhaler) bolus dağılımının akciğer kapasitesi arttıkça arttığını vurgulamışlardır. Partikül yüklü inhaler havadan akciğer içinde kalan havaya (residual hava) partiküllerin net taşınımı, sebebi tam olarak açıklanamayan tersinmez süreçlerin bir sonucu olarak meydana geldiği bildirilmiştir. $\mathrm{Bu}$ durum, olası taşıma mekanizmalarının ve bunların sebeplerinin araştırılmasını tetiklemiştir. Özellikle akciğerin derin bölgelerinde, yani 15.nesil sonras1 alveolar bölgedeki viskoz akışlarda, partikül taşınımının nasıl gerçekleştiği oldukça önemlidir.

Literatürde asinus bölgede ve etrafi alveollerle kaplı bronşiol model kullanılarak partikül birikiminin incelendiği bazı çalışmalar bulunmaktadır. Darquenne ve Paiva (1996), tek yönde sabit akış koşulları altında alveollü kanal yapısına benzeyen iki boyutlu ve üç boyutlu modeller geliştirmişlerdir. $2 \mathrm{D}$ ve $3 \mathrm{D}$ modeller arasında partikül birikiminde önemli farklılıklar belirlenmiş ve bu durumun modellerin kendine has partikül dinamiklerinden kaynaklandığ bildirilmiştir. Alveollü kanal modelini kullanarak iki yönlü (nefes alıp verme) akış koşullarının dikkate alınarak partikül dinamikleri ilk olarak 
Tsuda ve Henry (1985) tarafından incelenmiştir. Ritmik olarak daralan ve genişleyen alveollü bir kanalda oldukça karmaşı ve tersinmez akışların gerçekleştiği rapor edilmiştir. Sznitman vd. (2009), alveolar akışları ve partikül birikimini hem bir kanala monte edilmiş küresel alveol modelinde hem de iki yönlü akış şartı için hareketli sınırları olan bir asiner model kullanarak simüle etmişlerdir. Partikül yörüngelerinin ve birikiminin alveolar yerleşimle kuvvetli bir şekilde ilişkili olduğu bulunmuştur. Ayrıca, salınımlı konveksiyon akışın $1 \mu \mathrm{m}$ çapındaki partiküller üzerinde büyük bir etkiye sahip olduğu bildirilirken, $3 \mu \mathrm{m}$ çapındaki partiküller için bu etki yerçekimine nazaran daha azdır. Alveollü kanallarda hava akışı ve partikül dinamikleriyle ilgili deneysel çalışmalar hem büyütülmüş modellerde (Berg ve Robinson, 2011) hem de gerçek ölçülerdeki modeller üzerinde (Sznitman vd., 2010; Fishler vd., 2015) gerçekleştirilmiştir. $\mathrm{Bu}$ çalışmalar sonuçları itibariyle sayısal çalışmalarla (Harding ve Robinson, 2010; Katan vd., 2016) iyi bir uyum sergilemiştir.

Tsuda vd. (1995) ve Henry vd. (2002) tarafindan yapılan bir çalışmada, alveol kesesi içerisindeki akışın resirkülasyonuna bağlı olarak partiküllerin hareketinde bir değişim gözlenmiştir. Henry vd. (2009), sabit duvarlı bir salınımlı akış modelinde konvektif taşınımın gerçekleşmesi için alveollerin varlığının yeterli olduğunu göstermiştir. Elde edilen bu sonuçlar, aerosol taşınım mekanizmalarının temelinde geometrik özelliklerin önemli bir rol oynayabileceğini göstermiştir. Sarangapani ve Wexler (1999), taşınım mekanizmasının çok sayıda nefes döngüsüyle açıklanabileceğini ve bu nedenle tek bir nefes çevrimine göre gözlemlenen partikül dağılımının tam sonuç vermeyeceğini bildirmişlerdir. Diğer bir çalışmada ise araştırmacilar, 30 adet yumru şeklinde alveol hücre kullanılmış ve belirli kabuller altında nefes alma (inspirasyon) ve verme (ekspirasyon) modellenmiştir (Lee ve Lee, 2003).

Şimdiye kadar yapılan çalışmalarda alveolar duvarları sabit ve hareketli kabul edilerek alveollü ve alveolsüz hava kanalları arasındaki partikül dağılımı incelenmiştir. Bu deneysel ve sayısal çalışmalarda partikül davranışlarıyla ilgili çeşitli olası nedenler öne sürülse de, asinustaki konvektif partikül dağılımı mekanizması üzerine tutarlı ve somut kanıtlar ortaya konamamıştır. Darquenne ve Prisk (2003), aerosol bolus dağılımı üzerine sayısal ve deneysel sonuçları değerlendirmişlerdir. Çalışmalarında, çapı 0.5 ve $1 \mu \mathrm{m}$ partiküller için, yerçekimsiz ortamda aerosol dağılımının partikül boyutuna bağlı olmadığı gözlenmiştir. Olası nedenlerden birinin akışın kendisinin neden olduğu bir karışım hareketi olduğu öne sürülmüştür. Darquenne ve Prisk (2004) daha sonra asiner akışta taşınımı incelemek için bir ters akış mekanizması tasarlamışlardır. Çalışmalarında partikül bolusu, iki farklı penetrasyon miktarında mikro yerçekimi altında solunmuş ve birkaç tersine akış ve nefes tutma şartları uygulanmıştır. Araştırmacılar, akım çizgilerinde uzama ve kıvrılmanın uygulanan ters akış süreçlerinde gözlenmediğini ve bu olayların tam akış döngüsünün gerçekleştiği bir solunum çevrimi sırasında oluştuğunu tespit etmişlerdir.

Özet olarak, şimdiye kadar solunum bronşiyollerinde ve alveolar kanallarda partikül birikimi üzerine bir dizi çalışma yapılmıştır. Ancak alveol keselerinde partikül birikimi ile ilgili çalışmalar azdır. Alveolar hava akışı alveol duvarlarının ritmik olarak genişlemesi ve daralması ile gerçekleşir. Aksine, respiratuar bronşiyollerinde ve alveol kanallarında ise solunan havanın çoğu bronșiyolar kanallarda kalır ve havanın sadece küçük bir kısmı kanal etrafındaki alveollere girmektedir (Tsuda vd., 1985). Sonuç olarak, asinusta hava akışı ve partikül dinamikleri terminal alveollerde ve ileri nesillerdeki alveollü kanallarda oldukça farklı olabilmektedir. Kumar vd. (2009) tarafindan yapılan bir çalışmada, bal peteği formundaki respiratuar bronşiyol, alveolar kanal ve ucu kapalı terminal alveol modellerinde hava akışı sayısal olarak incelenmiştir. Duvar hareketlerinin respiratuar bronşiol ve alveolar kanal da resirkülasyon akışını tetiklediği ve terminal alveol modelinde ise resirkülasyon akışına rastlanmadığını rapor edilmiştir. Kumar vd. (2011) bir diğer çalışmalarında, respiratuar bronşiyol ve alveolar kanalda taşınımla dağılımı incelemişlerdir. Çalışmalarında sürekli akışın asiner akışlarda önemli bir karışım mekanizması olduğunu kütlesiz sıvı parçacıklarını izleyerek tespit etmişlerdir. Ancak, bu iki çalışmada terminal alveollerin içindeki parçacık davranışları üzerindeki duvar hareketi etkileri araştırılmamıştır. $\mathrm{Bu}$ çalışmanın amacı, insan akciğerinin asinus bölgesinde bulunan bir respiratuar bronşiol model üzerinde ritmik olarak hareket eden bir alveoldeki hava akışı ve partikül dinamiklerini çoklu nefes periyotlarında ve farklı solunum şartlarında sayısal olarak incelemektir. İlk solunum çevrimi sadece hava için gerçekleştikten sonra ikinci çevrimde model girişinden farklı çaplarda aerosol partikülleri salınmıştır. Simülasyonlar üç nefes çevrimi için gerçekleştirilmiş ve aerosol partiküllerinin yörüngeleri sayısal çözüm boyunca takip edilmiştir. Böylece bu çalışmada bir respiratuar bronşiol modelde hava akışı ve partikül 
dinamikleri karakterize edilmiş ve değişen fizyolojik faktörlerin partikül birikimi üzerine etkisi araştırılmıştır.

\section{Gereç ve yöntem}

İnsan akciğerinin asinar bölgesine ait bir respiratuar bronşiol'ü (jenerasyon 17, G17) temsil eden 3B geometrik model Şekil 1'de gösterilmektedir. Bu şekilde, bir lümen hava kanalı etrafinda kısmen yerleşmiş alveol keseleri görülmektedir. Alveol keselerinin dış duvarları bir nefes çevrimi süresince hareketli olduğu ve $\% 25$ oranında kanal duvarlarıyla birlikte her yönde aynı oranda genişleyip daraldığı kabul edilmiştir. İnspirasyon durumunda akışkan soldan sağa doğru, ekspirasyon esnasında ise sağdan sola doğru hareket etmektedir. Lümen kanalından giren havaya ait ortalama $\mathrm{Re}$ sayıs $\left(\mathrm{Re}=\mathrm{U}_{0} \mathrm{D} / v\right)$ ortalama kanal giriş hızı ve kanal çapı dikkate alınarak hesaplanmıştır. Hesaplamalarda partiküllerin kanaldaki hava hareketi üzerine önemli bir etkisinin olmadığı kabul edilmiştir (one-way coupling). Akış alanı zamana bağlı ve üç boyutlu Navier-Stokes denklemleri sıkıştırılamaz akış kabulü kullanılarak Arbitrary Lagrange-Euler modeli (Xia and Lin, 2008; Xia vd., 2010) ile ANSYS Fluent ticari paket programı kullanılarak sayısal olarak çözülmesiyle belirlenmiştir. Korunum denklemleri doğrusal olmadığından ve birbirine bağlandığından, çözüm süreci, tüm korunum denklemleri kümesinin çözüm yakınlaşana kadar tekrar tekrar çözüldüğü tekrarlamaları içermektedir. Fluent paket programında Coupled şeması kullanılarak basınç ve hız parametreleri zamana bağlı olarak birlikte çözülmüştür. Gradyan için Least squares cell based, basınç için Presto ayrıklaştırma şeması ve momentum için Second order upwind şeması kullanılmıştır.

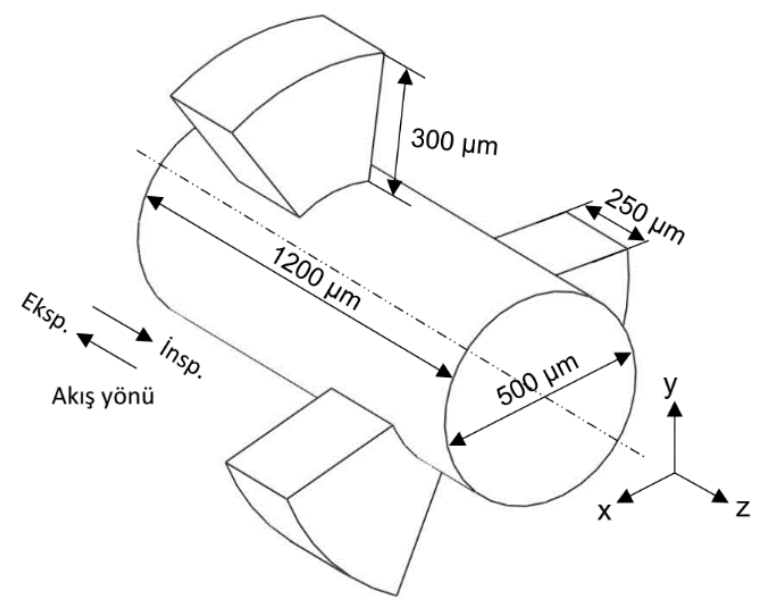

Şekil 1. Asinus bölgesinde bir respiratuar bronşiol için geometrik model
Sayısal çalışmada ağ bağımsız çözümler için model ilk olarak 995,248 tetrahedral elemana ayrıştırılmıştır. Sonraki ağ yapıları için eleman sayıları 1,640,236 ve 2,415,651 olarak alınmıştır. Üç ağ yapısı için ortalama kanal hızı $\left(\mathrm{U}_{0}\right)$ değeri hesaplatılmıştır ve kalın ve en ince ağ yapısı için yaklaşık \%0.4 hata gerçekleşmiştir. Bu nedenle akış alanı yaklaşık bir milyon tetrahedral elemana ayrıştırılmıştır. Nefes alma (inspirasyon) ve verme (ekspirasyon) süreleri 2'şer saniye seçilmiş (dakikada 15 normal solunum şartına karşılık) ve üç ardışık nefes çevrimi uygulanmıştır (toplam nefes periyodu, $12 \mathrm{~s}$ ). Hesaplamalar ortalama debi değerleri dikkate alınarak hafif $(\mathrm{Q}=15 \mathrm{~L} / \mathrm{dk}$, $\mathrm{Re}=0.29)$, normal $(\mathrm{Q}=30 \mathrm{~L} / \mathrm{dk}, \mathrm{Re}=0.58)$ ve ağır $(\mathrm{Q}=60 \mathrm{~L} / \mathrm{dk}, \mathrm{Re}=1.16)$ solunum koşuluna karş1l1k gelen üç farklı solunum şartında gerçekleştirilmiştir. Sayısal çözümde bu debi değerlerine karşı1ık gelen akışkan hızı değerleri (sırasıyla, $0.0097,0.00194$ ve $0.0389 \mathrm{~m} / \mathrm{s}$ ) giriş sınır şartı olarak alınmıştır. Diğer taraftan, kanal duvarları esnek kabul edilmiş ve cidarda kaymama sınır koşulu tanımlanmıştır. Model boyunca başlangıç basıncı $101 \mathrm{kPa}$ (atmosferik basıncı) olarak ayarlanmıştır. Simülasyonlarda çapları 1 ila $10 \mu \mathrm{m}$ aralığında rastgele seçilmiş on farklı çapa sahip ve $1100 \mathrm{~kg} / \mathrm{m}^{3}$ yoğunluğunda küresel aerosol partiküller kullanılmış ve havanın ise $37^{\circ} \mathrm{C}$ sıcaklığındaki fiziksel özellikleri dikkate alınmıştır. Daha büyük çaplı partiküller yüksek atalet kuvvetlerinden dolay1 asiner bölgeye ulaşamazlar (Talaat ve Xi, 2017). Bu nedenle maksimum partikül çapı $10 \mu \mathrm{m}$ olarak alınmıştır. Simülasyonlarda kullanılan partiküller ikinci nefes çevrimi başında ( $\mathrm{t}=4 \mathrm{~s})$ model girişinden hesap alanına salınmıș ve üçüncü nefes çevriminin sonuna kadar takip edilmiştir ( $\mathrm{t}=12 \mathrm{~s})$. Aerosol partiküllerinin modele giriş hızları hava giriş hızıyla aynı olduğu kabul edilmiştir. Tüm hesaplamalarda zaman adımı $0.05 \mathrm{~s}$ ve yakınsama kriteri $10^{-6}$ olarak alınmıştır. Simülasyonlar $32 \mathrm{~GB}$ RAM ve iki adet $2.30 \mathrm{GHz}$ Intel Xeon CPUs barındıran DELL marka bir iş istasyonu kullanılarak yapılmıştır. Üç nefes çevrimi için ortalama simülasyon süresi 15 saattir.

\section{Bulgular ve tartışma}

Düşük Re sayılı akış nedeniyle, akış şartları kanal çap değerinden çok daha küçük bir mesafede tam gelişmiş olmaktadır. Bu nedenle kanal girişinde (i) sinüzoidal dalga formunda parabolik bir hız profili, kanal çıkışında (o) ise homojen Neumann çıkış akış koşulları $\left(p_{x}=(1 / R e)\left(u_{x x}+u_{y y}\right)\right)$ uygulanmıştır (Şekil 2). Burada Re sayısı iki boyutlu kanal yüksekliği kullanılarak $\mathrm{Re}=\mathrm{U}_{0} \mathrm{H} / v$ bağıntısı ile belirlenmiştir. Simülasyonlar üç farklı 
solunum şartına karşılık gelen üç farklı Re sayısı koşulunda gerçekleştirilmiş̧ir $(\operatorname{Re}=0.29,0.58$ ve 1.16). Bu çalışmada kullanılan respiratuar bronşiol medel yazarın bir önceki çalışmasında (Ciloglu (2020)) kullanılan model ile aynıdır. Burada elde edilen sayısal sonuçların doğruluğu, Ciloglu (2020) çalışmasında yapılmıştır, ki orada partikül birikimi için elde edilen sayısal değerler Darquenne (2009) tarafindan elde edilen değerler ile karşılaştırılmış ve verilerin bir uyum içerisinde olduğu sunulmuştur. $\mathrm{Bu}$ çalışmada uygulanan düşük $\mathrm{Re}$ sayılı akışlar, insan akciğerinin asiner bölgesinde gerçekleşen akış şartlarını karşılamaktadır (Kumar vd., 2011).

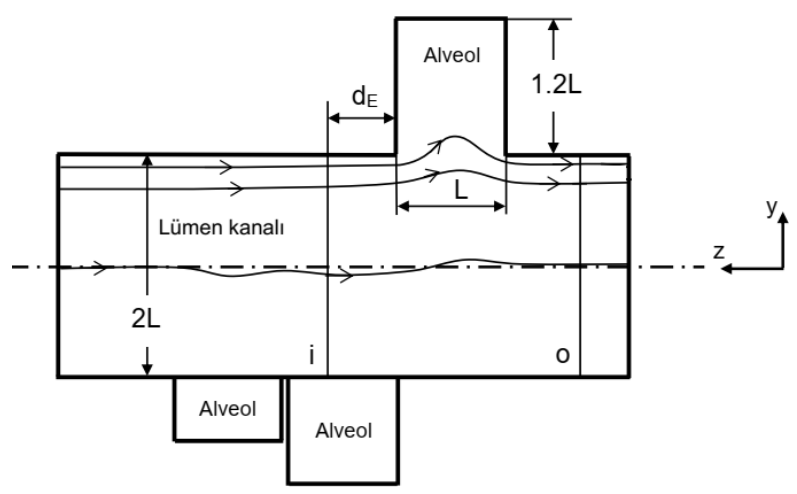

Şekil 2. İnspirasyon esnasında iki boyutlu respiratuar bronşiol kanalın şematik görünümü. Burada; L alveol giriş açıklığını, $\mathrm{d}_{\mathrm{E}}$ alveol giriş uzunluğunu, “i” parabolik hiz profilinin uygulandığın kanal girişini ve "o" Neumann çıkış akış koşullarının uygulandığı kanal çıkışını göstermektedir.

\subsection{Alveolar akış yapısı}

Şekil 3 'te inspirasyon durumunda $(\mathrm{t}=2 \mathrm{~s})$ farklı solunum şartları için üç boyutlu akım çizgileri gösterilmektedir. Burada, lümen kanalına giren havanın bir kısmının alveol çukuruna doğru yöneldiği ve burada bir girdap hareketi oluşturduğu görülmektedir. Bütün akış durumlarında alveollere hava akışının olduğu ve burada resirkülasyon (girdap) bölgelerinin meydana geldiği ve zamanla alveollerin distal kenarlarına (D) ulaştı̆g 1 belirlenmiştir. $\mathrm{Bu}$ durumun, solunan ve residual hava arasında gaz değişimini tetikleyen biyolojik etkileri olabilir (Talaat ve Xi, 2017). Şekil 3(a)'da, hava akışının lümen kanalında simetrik olmasına rağmen, alveol içerisinde asimetrik olduğu görülmektedir. Asimetrik akış profilinin oluşması, alveollerin asimetrik yerleşiminin yanı sıra, kanal içi akış her ne kadar düşük Re sayılı bir akış olsa da atalet etkilerinin azda olsa akışı etkilemesi nedeniyledir. Şekil 3(b) ve (c)'de alveol giriş ağzındaki akım çizgileri incelendiğinde, akış ayrilmasının alveolün proksimal $(\mathrm{P})$ duvar kenarlarına yakın bir şekilde gerçekleştiği görülmektedir.

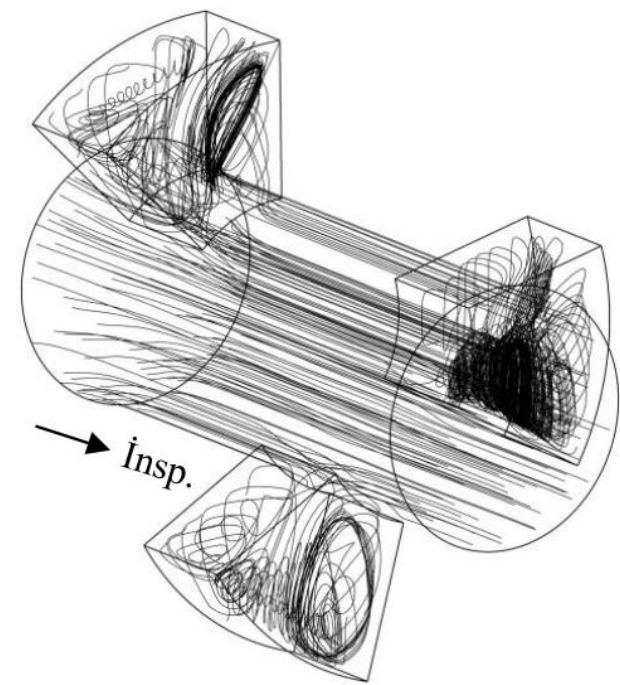

(a)

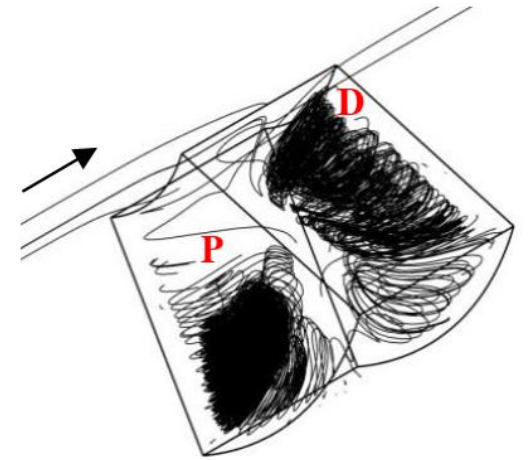

(b)

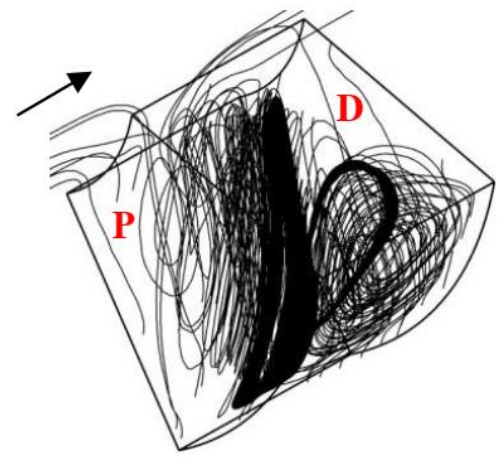

(c)

Şekil 3. İnspirasyon durumunda ( $\mathrm{t}=2 \mathrm{~s}$ ) (a) $\mathrm{Q}=15 \mathrm{~L} / \mathrm{dk}$ ve $\mathrm{Re}=0.29$ için üç boyutlu respiratuar bronşiol kanalda akım çizgileri, (b) $\mathrm{Q}=30 \mathrm{~L} / \mathrm{dk}$ ve $\mathrm{Re}=0.58$ için alveolar akışta akım çizgileri ve (c) $\mathrm{Q}=60 \mathrm{~L} / \mathrm{dk}$ ve $\mathrm{Re}=1.16$ için alveolar akışta akım çizgileri (Burada; P: proksimal duvar, D: distal duvar).

Genel olarak alveollü bir kanalda hava akıșı alveollerin ritmik olarak genişlemesine ve daralmasına bağlıdır (Kumar vd., 2009). Alveolar duvar hareketinin neden olduğu bu alveolar çekme kuvveti ile bağlantılı olarak, kanalın çevresindeki alveollere az miktarda kanal hava akışının saptığı gözlenmektedir. Proksimal bölgede alveolar boşluğun boyutu kanal çapına göre çok daha küçüktür. Bu nedenle kanal akışının çok az bir kısmı alveollere girer, ancak alveol girişine yakın 
bu akım her ne kadar az miktarda olsa da alveol çukurunda girdap hareketi oluşturabilir. Şekil 3'te görüldüğü gibi, elde edilen sonuçlar kanal akışıyla karşılaştırıldığında alvolerdeki hava akışı resirkülasyonlu akış özelliği sergilediğini göstermiştir. Böylece, asinusun proksimal bölgesinde (asinusun ilk birkaç nesli) alveolar akış, tipik olarak proksimal duvar (P) yakınında meydana gelen bir resirkülasyon akış hareketiyle meydana geldiği söylenebilir (Şekil 3). Diğer taraftan, lümen kanalı ve alveoller arasındaki akış etkileşimi, yine alveolar duvarların genişlemesi ve daralmasının bir sonucu olarak ortaya çıkan bir sürüklenme bölgesi aracılığıyla gerçekleşir. $\mathrm{Bu}$ nedenle lümen kanalından alveollere ve alveollerden kanala doğru olan akışkan hareketi, proksimal duvar kenarına $(\mathrm{P})$ yakın bir bölgede gerçekleşmiştir (Henry vd., 2002; Kumar vd., 2009). Asiner bölgenin ilerisindeki nesillerde (distal) ise alveoller içindeki resirkülasyonlu akış, radyal akışa dönmektedir. Buna kanal boyunca azalan kesme kuvveti neden olmaktadır. Böylece G23 neslinde alveol içindeki akış tamamen radyal akışa dönmektedir (Ciloglu, 2020). Bu nedenle distal akciğer nesillerindeki hava kanallarından alveollere kütle transferinin arttığı söylenebilir.

Şekil 4'te görüldüğ̈ gibi, ekspirasyon durumunda akış özellikleri akış yönünün tersine çevrilmesi dışında inspirasyon fazıyla hemen hemen aynıdır. Ekspirasyon sırasında, asiner bölgenin distalinde ortaya çıkan radyal akışlı hava alveol boşluklarından lümen kanalına doğru yönelir. Benzer şekilde, proksimal bölgedeki alveollerdeki akışın yönü de ekspirasyonla tersine döner. Hava akış yönünün tersine dönmesi sırasında, düşük inspirasyon akış hızından kaynaklanabilecek kararsız akış tersinmezlikleri ortaya çıkabilir.

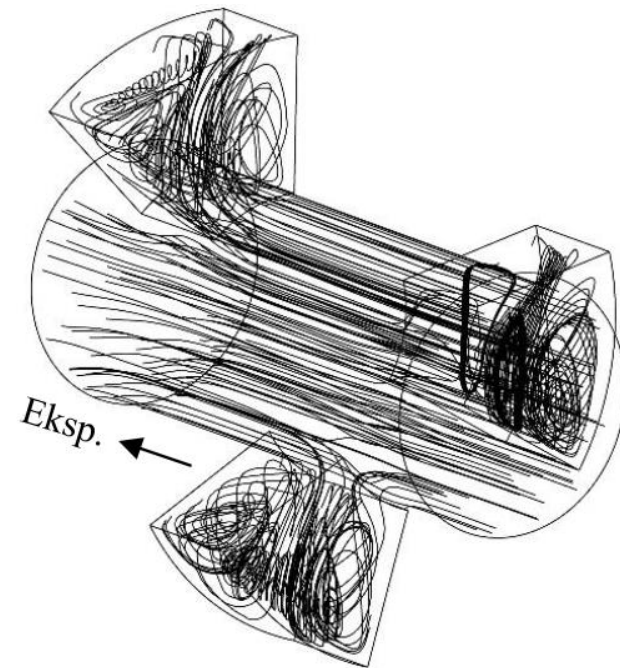

(a)

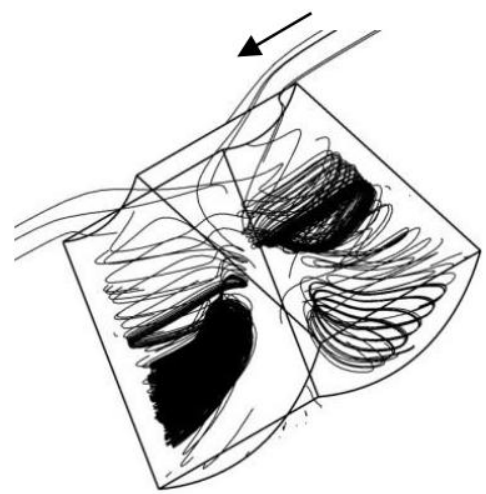

(b)

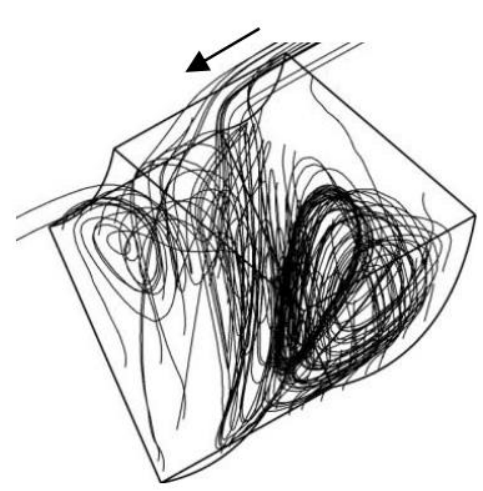

(c)

Şekil 4. Ekspirasyon durumunda ( $\mathrm{t}=4 \mathrm{~s}$ ) alveolar akışa ait üç boyutlu akım çizgileri; (a) $\mathrm{Re}=0.29$, (b) $\operatorname{Re}=0.58$ ve (c) $\operatorname{Re}=1.16$.

Ayrıca Şekil 4'te görüleceği üzere, inspirasyon sırasında akış alanında ortaya çıkan resirkülasyon bölgeleri ekspirasyon sirasinda tamamen kaybolmamıştır. Bu artık girdaplar, salınımlı akışlarda gözlenen bir olay olan ve yukarda bahsedilen akış tersinmezliklerinden kaynaklanmış olabilir ve ayrıca partiküllerin taşınımı ve birikimi bu artık girdaplardan etkilenebilir (Ottino vd., 1988; Tsuda vd., 2002).

\subsection{Alveolar partikül dağılımı}

$\mathrm{Bu}$ çalışmada ağız yoluyla alınan ve çapları 1 ila 10 $\mu \mathrm{m}$ aralığında değişen 50000 adet aerosol partikül dikkate alınmıştır. Partiküller, inspirasyon fazında model girişinden sürekli enjeksiyonla enjekte edilmiş ve model duvarlarında birikene ya da modeli terk eden kadar sayısal olarak takip edilmişlerdir. Yerçekimi negatif y yönünde alınmıştır (Şekil 1). $15 \mathrm{~L} / \mathrm{dk}$ akış debisinde ve model girişinden hava hızıyla aynı hızda salınan aerosol partiküllerinin ikinci inspirasyon fazı sonrası ( $\mathrm{t}=6 \mathrm{~s})$ kanal ve alveol içindeki durumları Şekil 5'te gösterilmektedir. Burada aerosol partiküllerinin çoğu lümen kanalındaki hava akışı vasıtasıyla taşındığı görülmektedir. Şekil 6'da akış debisi sirasıyla 15,30 ve $60 \mathrm{~L} / \mathrm{dk}$ ve tidal hacim $1000 \mathrm{ml}$ olan ve inspirasyon/ekspirasyon fazlarında aerosol partiküllerinin dağılımları xydüzleminde gösterilmektedir. Alveol duvarlarının ritmik hareketi sayesinde lümen kanalından alveolar ağıza doğru gelen partiküllerin bir kısmı 
alveol boşluğuna doğru yönelmiştir. Bu durumda, bu parçacıklar geldikleri konuma geri dönemeyebilir, yani alveol duvarlarında birikebilir ve tedavi sürecini etkileyebilirler. Ayrıca, lümen kanalı boyunca hareket eden partiküllerin kanalda kalma süreleri alveollere yönelen az miktardaki partikülden daha kısadır. $\mathrm{Bu}$ nedenle incelenen kanaldaki partiküllerin net dağılımının, özellikle eksenel yönde dağılım mekanizmasıyla gerçekleşmiştir. Sayısal sonuçlara göre, partikül çapının artışıyla partikül birikimi azalmıştır. Genel olarak, çap $7 \mu$ m'nin altındaki aerosol partiküller alveol boşluklarına yönelmişlerdir. Daha büyük partiküllerin çoğu sahip oldukları yüksek ataletleri nedeniyle lümen kanal cidarına yakın hareket ederek ya kanal cidarında tutunmuştur ya da kanalı terk etmiştir (Şekil 6, t=6 s). Şekil 6 da ayrıca, Re sayısındaki artışla, solunum süresi boyunca model içerisinde biriken partiküllerin sayısında azalma olduğu görülmektedir. Böylece, akış debisindeki artışla daha fazla partikülün distal bölgelere iletildiği ve bu bölgelerde tutunmuş olabileceği söylenebilir. $\mathrm{Bu}$ nedenle, respiratuar bronşiol modelde aerosol birikiminin partikül boyutu ve akış debisiyle azaldığı sonucu çıkarılabilir.

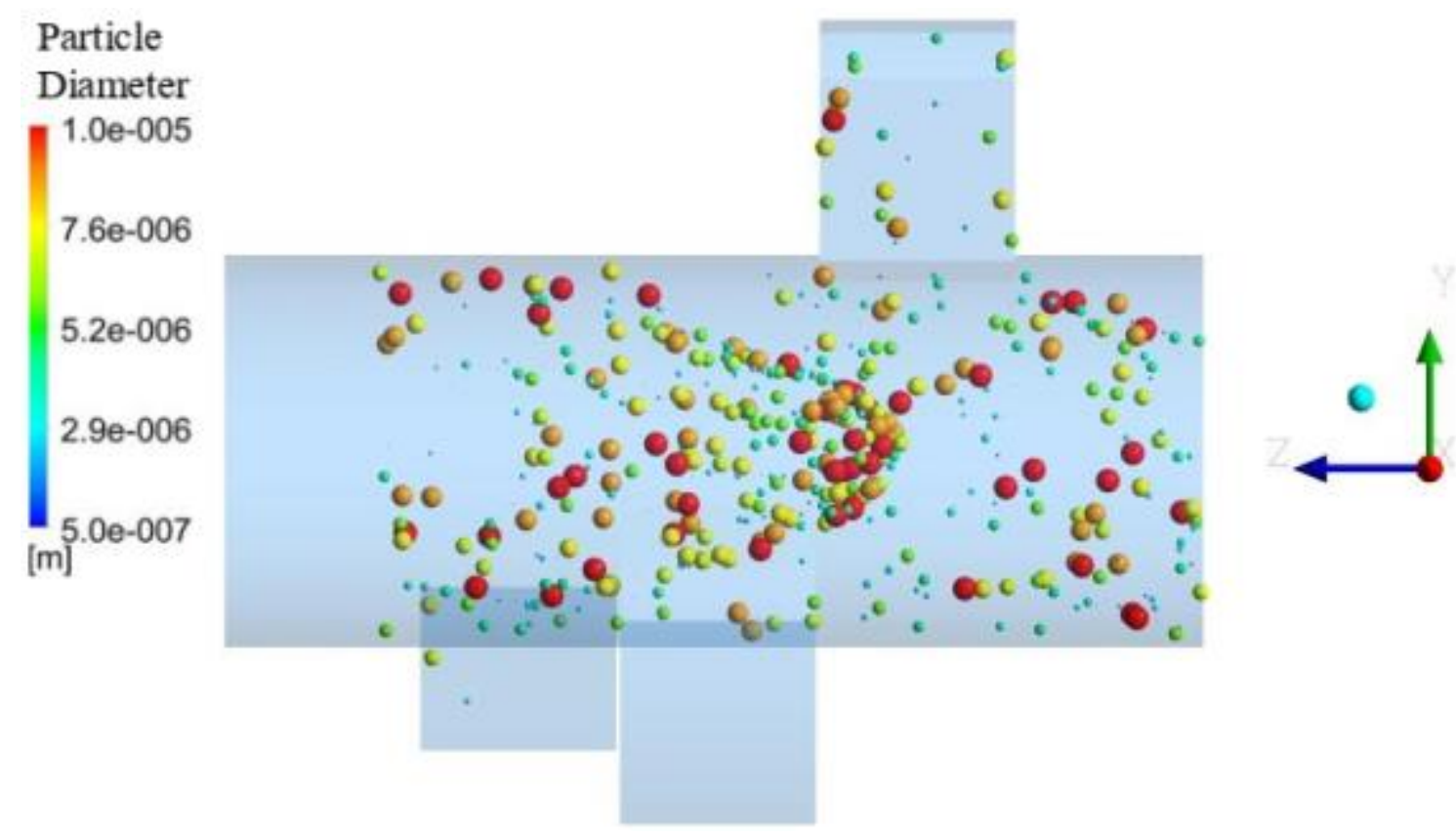

Şekil 5. Respiratuar bronşiol modelde ikinci inspirasyon fazı sonrası $(\mathrm{t}=6 \mathrm{~s})$ aerosol partiküllerinin dağılımı $(\mathrm{Q}=15 \mathrm{~L} / \mathrm{dk}$ ve $\mathrm{Re}=0.29)$.

Şekil 6'da ayrıca, ekspirasyon fazı sonrasında ( $\mathrm{t}=8$ ve $\mathrm{t}=12 \mathrm{~s}$ ) aerosol partiküllerinin durumu da görülmektedir. Ekspirasyon fazı sırasında, partiküller pulmoner bölgenin dışına yani üst akciğer nesillerine doğru hareket etmişlerdir. Dolayısıyla inspirasyon fazının aksine, expirasyonda partikül birikiminin proksimal bölgelerde daha yüksek olması beklenmektedir. Ekspirasyon sirasında alveollerin içinde bulunan partiküllerin bir kısmı alveolün kasılma hareketi nedeniyle lümen kanalına doğru geri çekilmiştir. Ancak, alveol içindeki hava akış hızı lümen kanalındakinden çok daha düşük olduğu için, ekspirasyon sırasında parçacıkların geriye doğru olan hareketleri de zayıftır ve böylece yüzeyde tutunma eğilimleri yüksektir. Buna yerçekiminin de etkisi eklenince ekspirasyon sirasinda partiküllerin yörüngeleri, inspirasyon fazından farklı olmuștur. Ekspirasyon fazı sırasında yerçekimi etkisi, partiküllerin kalma sürelerini artırmıştır ve dolayısıyla daha fazla sayıda partikül birikmiștir. Sonuç olarak, partiküllerin küçük bir kısmı ekspirasyon sonunda geometriden çıkmıștır. Daha büyük çaplı partiküller proksimal bölgede birikime yatkınken, daha düşük çaptaki partiküller orta (G18-G21) ve son nesillerde (G22-G23) daha fazla birikim gösterebilir (Ciloglu, 2020). Bu durum, proksimal bölgede asılı halde bulunan çok sayıda büyük çaplı partikülden kaynaklanmaktadır. $\mathrm{Bu}$ asılı partiküllerin çoğu son inspirasyon fazında tekrar inhale olmuştur. Düşük inspirasyon akış debisi nedeniyle, bu asılı partiküller ekspirasyon esnasında orta asiner bölgeye kadar ulaşırlar ve sedimentasyon nedeniyle proksimal alveolar bölgede birikime eğilimlidirler. 

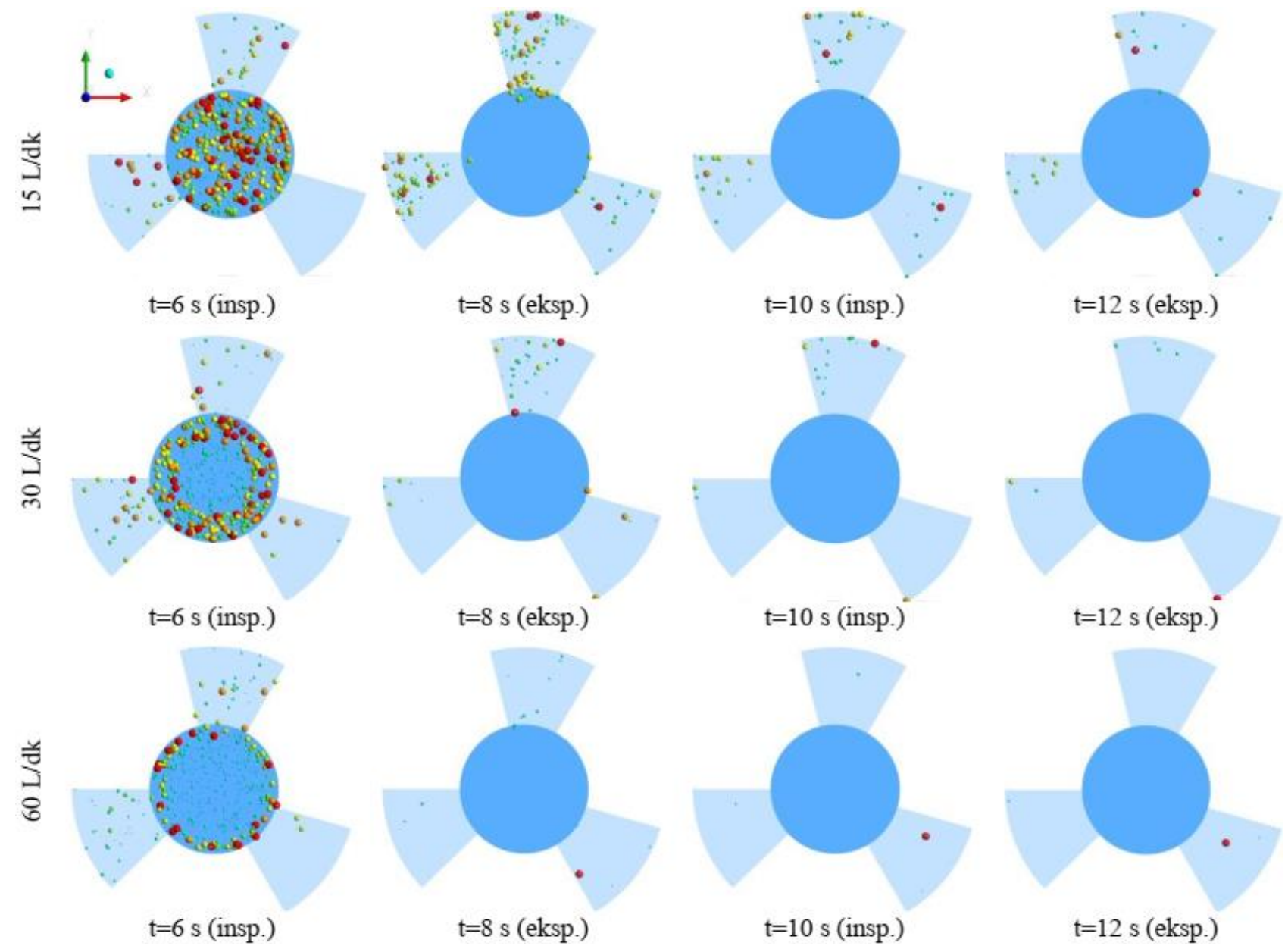

Şekil 6. Respiratuar bronşiol modelde solunum periyodu süresince aerosol partiküllerinin dağılımı.

Üçüncü solunum çevrimi sırasında, kalan partiküller asinusun distal bölgelerine doğru hareket ettiği için kanal içerisinde hiçbir partikülün kalmadığ1 görülmektedir (Şekil $6, \mathrm{t}=10 \mathrm{~s}$ ). Diğer taraftan, alveol çukurlarında ise özellikle çapı 5 $\mu$ m'nin altındaki aerosol partiküllerinin biriktiği belirlenmiştir. Sonraki solunum döngülerinde ise respiratuar bronşiol modelde askıda kalan tüm parçacıklar asinusun daha da aşağısına taşınacak ve buradaki alveol keselerinde birikecektir.

\section{Sonuçlar}

$\mathrm{Bu}$ çalışmada, insan akciğerinin asiner bölgesinde bulunan bir respiratuar bronşiol modelindeki alveollerde hava ve farklı boyutlardaki aerosol partiküllerinin partikül dinamikleri farklı solunum şartlarında (hafif, normal ve ağır solunum) ve ardışık nefes periyotlarında CFD kullanılarak sayısal olarak incelenmiştir. $\mathrm{Bu}$ çalışmada kullanılan aerosol partiküllerinin Lagrange sürüklenmesiyle hareketlerini izlemek için modellenen respiratuar bronşiol kanalı üzerindeki alveoller, bir giriş ağzı bulunan basit çukursu geometriler olarak düşünülmüştür. Böylece, lümen kanalında ve bir alveol içindeki partikül dinamiklerini ve bunların birbirleriyle etkileşimini incelemek mümkün olmuştur.

Elde edilen sonuçlara göre, ritmik alveollar duvar hareketi alveollere doğru olan alveolar hava hareketini tetiklemiştir. Tüm akış durumlarında lümen kanalında simetrik bir akış profili meydana gelirken, alveollerde ise asimetrik bir akış profili ve girdaplı yapılar gözlenmiştir. Respiratuar bronşiol modelde partikül dinamikleri genel olarak eksenel hava akışıyla karakterize olmuştur. İnspirasyon ve ekspirasyon fazlarında aerosol partiküllerinin yörüngelerinin farklı olduğu gözlenmiştir. Elde edilen sonuçlar, respiratuar bronşiol modelde aerosol birikiminin partikül boyutu ve akış debisiyle azaldığını göstermiştir. Çap1 $7 \mu$ m'nin üzerindeki aerosol partiküllerinin kanal cidarlarında biriktiği ve çapı $5 \mu \mathrm{m}$ 'nin altındaki partiküllerin çoğunun ise alveol boşluklarında biriktiği belirlenmiştir. Sonuç olarak, aerosol partiküllerinin çapındaki azalma ve akış debisindeki artışla daha fazla partikülün distal bölgelere iletildiği ve bu bölgelerde tutunmuş olabileceği söylenebilir. Ekspirasyon esnasında aerosol partiküllerinin bir k1smı alveollerden lümen kanalına doğru çekilerek asiner bölgenin 
dışına çıkmışlardır, yani akciğerin daha üst nesillerine doğru hareket etmişlerdir. Bu çalışmada elde edilen sonuçlar alveollerin içindeki akış yapılarının resirkülasyon akışla önemli ölçüde değiştiğini rapor eden önceki çalışmalarla uyum içerisindedir (Henry vd., 2002; Darquenne vd., 2009; Kumar vd., 2009; Kumar vd., 2011). Elde edilen sonuçlar, ayrıca, solunan farmasötik veya zararlı partiküllerin alveolar bölgede durumu ile ilgili önemli fizyolojik sonuçlar sunmaktadır. $\mathrm{Bu}$ nedenle bu çalışma, Covid-19 sonrası kalıcı solunum sıkıntısı çeken hastalar için etkili tedavi yöntemlerinin geliştirilmesine katkı sağlayabilir.

Alveolar bölgenin derinlerinde yani distal nesillerdeki düşük Re sayılı akış, daralarak dallanan yapilar, alveol duvar hareketinin kararsızlı̆̆ı ve kanal-alveolar akış faz gecikmesi gibi farklı mekanizmalar sayesinde partiküllerin birikimi tanımlanabilir ve gelecekteki bir çalışmanın konusu olabilir. İnsan akciğerinin tüm asiner bölgesi için aerosol partikül birikiminin doğru bir şekilde tahmin edilmesi gerekir ve bu tahminlerin in-vivo çalışmalarılyla tamamen uyum sağlamayacağı unutulmamalıdır. Son zamanlarda yapılan çalışmalarda ise pulmoner bölgede hava ve partikül dinamiklerini simüle etmek için yüksek çözünürlüklü bilgisayarlı tomografi (CT) tabanlı alveol kesecikleri modelleri kullanılmıştır (Tawhai ve Lin, 2010). Geometrik varyasyonların yanında, inspirasyon ve ekspirasyon arasındaki dalga formu farklılıklarının ve duvar hareketinde kararsızlık gibi asimetri etkileri de henüz araştırılmamıştır.

\section{Kaynaklar}

Bennett, W.D. and Smaldone, G.C. (1985). Use of aerosols to estimate mean air-space size in chronic obstructive pulmonary disease. Journal of Applied Physiology, 64(4), 1554-1560. https://doi.org/10.1152/jappl.1988.64.4.1554

Berg, E.J. and Robinson, R.J. (2011). Stereoscopic particle image velocimetry analysis of healthy and emphysemic alveolar sac models. Journal of Biomechanical Engineering, 133(6), 061004. https://doi.org/10.1115/1.4004251

Ciloglu, D. (2020). A numerical study of the aerosol behavior in intra-acinar region of a human lung. Physics of Fluids, 32(10), 103305. https://doi.org/10.1063/5.0024200

Darquenne, C. and Prisk, G.K. (2003). Effect of gravitational sedimentation on simulated aerosol dispersion in the human acinus. Journal of Aerosol Science, 34(4), 405-418. https://doi.org/10.1016/s0021-8502(02)00187-8
Darquenne, C. and Prisk, G.K. (2004). Effect of small flow reversals on aerosol mixing in the alveolar region of the human lung. Journal of Applied Physiology, 2083-2089. https://doi.org/10.1152/japplphysiol.00588.2004

Darquenne, C. and Paiva, M. (1996). Two- and threedimensional simulations of aerosol transport and deposition in alveolar zone of human lung. Journal of Applied Physiology, 80(4), 14011414. https://doi.org/10.1152/jappl.1996.80.4.1401

Darquenne, C., Harrington, L. and Prisk, G.K. (2009). Alveolar duct expansion greatly enhances aerosol deposition: a three-dimensional computational fluid dynamics study. Philosophical Transactions of the Royal Society A, 367, 2333-2346. https://doi.org/10.1098/rsta.2008.0295

Fishler, R., Hofemeier, P., Etzion, Y., Dubowski, Y. and Sznitman, J. (2015). Particle dynamics and deposition in true-scale pulmonary acinar models. Scientific Reports, 5, 14071. https://doi.org/10.1038/srep14071

George, P.M., Wells, A.U. and Jenkins, R.G. (2020). Pulmonary fibrosis and COVID-19: the potential role for antifibrotic therapy. Lancet Respiratory Medicine, 2600(20), 1-9. https://doi.org/10.1016/S2213-2600(20)30225-3

Harding, E.M. and Robinson, R.J. (2010). Flow in a terminal alveolar sac model with expanding walls using computational fluid dynamics. Inhalation Toxicology, 22(8), 669-678. https://doi.org/10.3109/08958371003749939

Harrington, L., Prisk, G.K. and Darquenne, C. (2006). Importance of the bifurcation zone and branch orientation in simulated aerosol deposition in the alveolar zone of the human lung. Journal of Aerosol Science, 37(1), 37-62. https://doi.org/10.1016/j.jaerosci.2005.03.005

Henry, F.S., Butler, J.P. and Tsuda, A. (2002). Kinematically irreversible acinar flow: A departure from classical dispersive aerosol transport theories. Journal of Applied Physiology, 92(2), 835-845. https://doi.org/10.1152/japplphysiol.00385.2001

Henry, F.S., Laine-Pearson, F.E. and Tsuda, A. (2009). Hamiltonian chaos in a model alveolus. Journal of Biomechanical Engineering, 131(1), 011006. https://doi.org/10.1115/1.2953559

Heyder, J. (2004). Deposition of inhaled particles in the human respiratory tract and consequences for regional targeting in respiratory drug delivery. Proceedings of the American Thoracic Society, 1(4), 315-320. https://doi.org/10.1513/pats.200409-046TA 
Heyder, J., Blanchard, J.D., Feldman, H.A. and Brian, J.D. (1988). Convective mixing in human respiratory tract: Estimates with aerosol boli. Journal of Applied Physiology, 64(3), 12731278. https://doi.org/10.1152/jappl.1988.64.3.1273

Katan, J.T., Hofemeier, P. and Sznitman, J. (2016). Computational models of inhalation therapy in early childhood: Therapeutic aerosols in the developing acinus. Journal of Aerosol Medicine and Pulmonary Drug Delivery, 29(3), 288-298. https://doi.org/10.1089/jamp.2015.1271

Knudsen, L., Weibel, E.R., Gundersen, H.J.G., Weinstein, F.V. and Ochs, M. (2010). Assessment of air space size characteristics by intercept (chord) measurement: An accurate and efficient stereological approach. Journal of Applied Physiology, 108(2), 412-421. https://doi.org/10.1152/japplphysiol.01100.2009

Kumar, H., Tawhai, M.H., Hoffman, E.A. and Lin, C.L. (2009). The effects of geometry on airflow in the acinar region of the human lung. Journal of Biomechanics, 42(11), 1635-1642. https://doi.org/10.1016/j.jbiomech.2009.04.046

Kumar, H., Tawhai, M.H., Hoffman, E.A. and Lin, C.L. (2011). Steady streaming: A key mixing mechanism in low-Reynolds-number acinar flows. Physics of Fluids, 23(4), 1-21. 41902. https://doi.org/10.1063/1.3567066

Lee, D.Y. and Lee, J.W. (2003). Characteristics of particle transport in an expanding or contracting alveolated tube. Journal of Aerosol Science, 34(9), 1193-1215. https://doi.org/10.1016/S0021-8502(03)00097-1

Ottino, J.M., Leong, C.W., Rising, H. and Swanson, P.D. (1988). Morphological structures produced by mixing in chaotic flows. Nature, 333(6172), 419-425. https://doi.org/10.1038/333419a0

Sarangapani, R. and Wexler, A.S. (1999). Modeling aerosol bolus dispersion in human airways. Journal of Aerosol Science, 30(10), 1345-1362. https://doi.org/10.1016/S0021-8502(99)00027-0

Sznitman, J., Heimsch, T., Wildhaber, J.H., Tsuda, A. and Rosgen, T. (2009). Respiratory flow phenomena and gravitational deposition in a three-dimensional space-filling model of the pulmonary acinar tree. Journal of Biomechanical Engineering, 131(3), https://doi.org/10.1115/1.3049481

Sznitman, J., Sutter, R., Altorfer, D., Stampanoni, M., Rosgen, T. and Schittny, J.C. (2010). Visualization of respiratory flows from 3D reconstructed alveolar airspaces using X-ray tomographic microscopy. Journal of Visualization, 13(4), 337-345. https://doi.org/10.1007/s12650-010-0043-0

Talaat, K. and Xi, J. (2017). Computational modeling of aerosol transport, dispersion, and deposition in rhythmically expanding and contracting terminal alveoli. Journal of Aerosol Science, 112, 19-33. https://doi.org/10.1016/j.jaerosci.2017.07.004

Tawhai, M.H. and Lin, C.-L. (2010). Image-based modeling of lung structure and function. Journal of Magnetic Resonance Imaging, 32, 1421-1431. https://doi.org/10.1002/jmri.22382

Tsuda, A., Henry, F.S. and Butler, J.P. (1985). Chaotic mixing of alveolated duct flow in rhythmically expanding pulmonary acinus. Journal of Applied Physiology, 79(3), 1055-1063. https://doi.org/10.1152/jappl.1995.79.3.1055

Tsuda, A., Rogers, R.A., Hydon, P.E. and Butler, J.P. (2002). Chaotic mixing deep in the lung. Proceedings of the National Academy of Science USA, 99(15), 10173-10178. https://doi.org/10.1073/pnas.102318299

Xia, G, Tawhai, M.H., Hoffman, E.A. and Lin, C.-L. (2010). Airway wall stiffness and peak wall shear stress: A fluid-structure interaction study in rigid and compliant airways. Annals of Biomedical Engineering, 38(5), 1836-1853. https://doi.org/10.1007/s10439-010-9956-y

Xia, G. and Lin, C.-L. (2008). An unstructured finite volume approach for structural dynamics in response to fluid motions. Computers \& Structures, $\quad 86(7)$, 684-701. https://doi.org/10.1016/j.compstruc.2007.07.008 